Article

\title{
Sustainability and Resilience of Alternative Lifestyles: An Ethnography of Self-organizing Communities in South China
}

\author{
Peng Wang \\ The Department of Applied Social Science, The Hong Kong Polytechnic University, Hong Kong, China; \\ wong.wang@connect.polyu.hk; Tel.: +852-5489-5835
}

Received: 31 December 2019; Accepted: 13 February 2020; Published: 15 February 2020

\begin{abstract}
As a manifestation of sustainability, self-organizing communities (SOCs) have been proven to be increasingly related to the environmental issues and living space crisis in the urban areas. Many social groups regard self-organizing communities as an ideal alternative to the problems of rapid urbanization since they challenge unsustainable materialism and consumerism. To penetrate this idea into a wider range of socio-cultural, economic, and political activities, such communities are moving towards becoming economically cooperative social entities and are usually characterized by small scale, co-construction, and co-creation. Community studies further point out that contemporary communities are somewhat decentralized, giving members a good sustainable mix of freedom and togetherness. This means that, compared to traditional communes, individualized differences within self-organizing communities are more prominent. They are susceptible to different cultural and political contexts, which have received little attention from Chinese scholars. To fill this gap, this study adopts ethnographic approaches to explore the lifestyle experiments of a self-organizing community (AnotherLand) in South China. It reviews the difficulties associated with identifying and characterizing SOCs. It examines how this self-organizing community maintains its sustainability by experimenting with specific lifestyles (internal factors) and building extensive social networks (external factors). It further suggests that sustainability should be taken as an essential conceptual framework for embodying the success or failure of self-organizing communities.
\end{abstract}

Keywords: sustainability; self-organizing communities; alternative lifestyles; ethnography; China studies

\section{Introduction}

As an important manifestation of sustainability, self-organizing communities are a reflection of industrial capitalist political economies. They challenge the unsustainable concept of materialism and consumerism by building a shared value that is different from the predominant society [1]. Interdisciplinary scholars have often regarded self-organizing communities as a product of the later stages of the commune movement or green movement in Global North countries. They have described self-organizing communities as a romantic and unrealistic portrayal of a better life of pioneers and other minorities. Self-organizing communities are therefore considered to be limited in their ability to achieve the goals they set and in their utility as sites for social science research [2,3]. In response, the scholarship of community studies has pointed out that utopian experiments play a driving role in cultural criticism and social change [4-6]. Therefore, small-scale cooperatives and alternative production relations of self-organizing communities are conducive to guiding society to advance on the path of sustainable development.

According to the existing literature of self-organizing communities, this contemporary phenomenon has been proven to be increasingly related to environmental issues and the living 
space crisis in urban areas [7]. Many marginal groups regard such communities as an ideal alternative to the problems of modern society and try to introduce this concept into a wider range of socio-cultural, economic, and political activities. They intend to live and work in a value-sharing community to pursue a more sustainable lifestyle, and the choice of location is usually in suburban or rural areas. Besides, community studies point out that contemporary communities are somewhat decentralized, giving members a good sustainable mix of freedom and togetherness [8]. This means that, compared to traditional communes, individualized differences within self-organizing communities are more prominent, which highlights the influence brought by different cultural and political contexts. However, research on alternative communities has received little attention from Chinese scholars and remains poorly understood. To fill this research gap, empirical studies are needed in the context of China, especially considering that self-organizing communities are increasing in China.

In the past decade, the provinces on the southeast coast of China have made great progress in ecological civilization construction and sustainable development by making full use of the local natural resources. Fujian Province is one of the most representative and advanced areas of this development policy (Fujian Eco-Optimization Strategy Research Report, 2017). With superior climatic conditions and environmental quality, the nine regions of Fujian Province have successfully attracted many ecological farms and communities based there, becoming a popular destination for people to pursue a better way of life [9]. The location of this study, Minhou County, is one of the wealthiest areas in Fujian Province. Its geographic location can be seen in Figure 1. It is the first batch of open coastal counties with a permanent population of 715,000 (Minhou County Government Work Report, 2019). Influenced by urbanization, most of the residents of Minhou County moved from villages to urban areas [10]. Therefore, the farmland of many villages in Minhou County was idle, and old buildings there were also in danger of falling out of use. Some former villagers rented out their farmland to migrant farmers, while others sold it to the local government [10]. Under this circumstance, it was chosen as one of the experimental sites for the CSA (Community Supported Agriculture) model in southern China and aimed to build new villages with the sustainable themes of organic farming, community building, old house renovation, and cultural conservation.

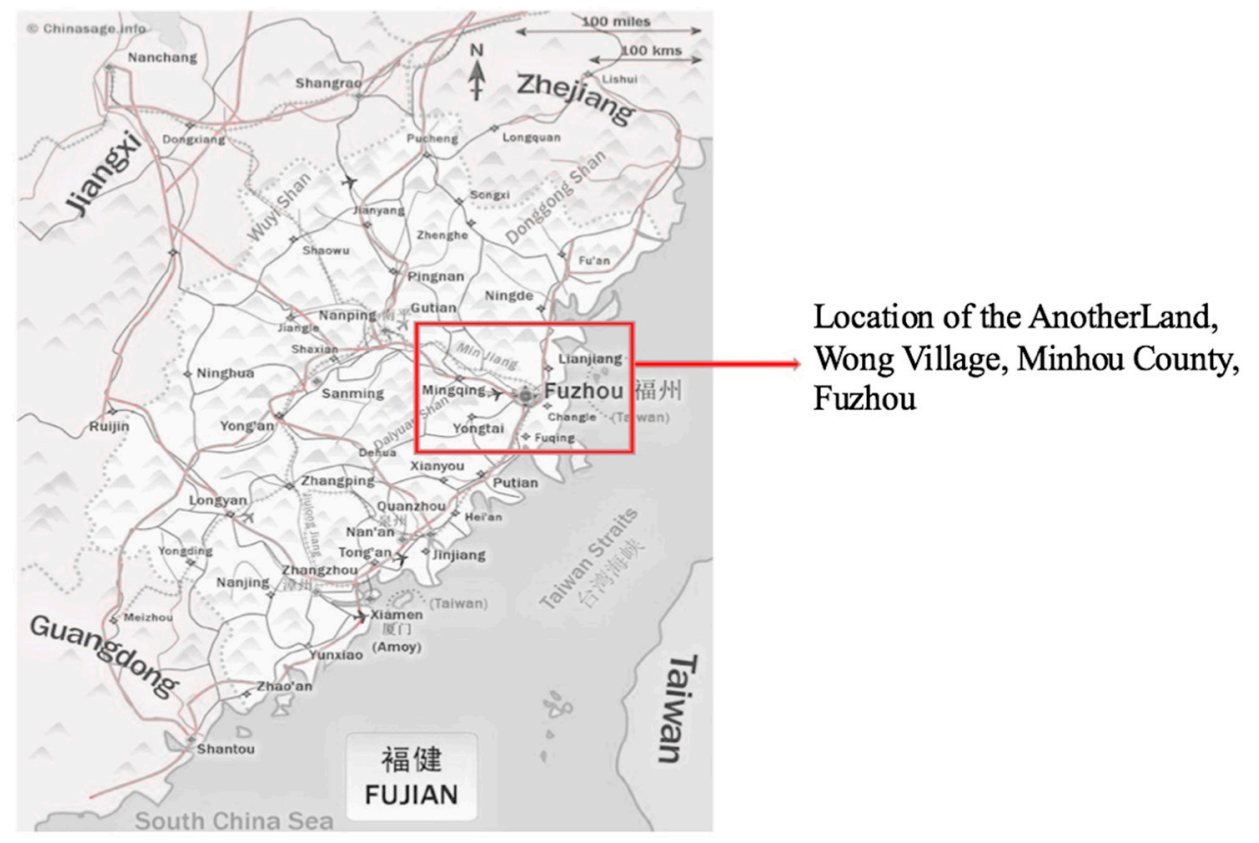

Figure 1. Location of AnotherLand, Minhou County, Fuzhou.

This study adopts an ethnographic approach to explore the lifestyle experiments of a self-organizing community (AnotherLand) in South China. It aims to understand how this self-organizing community maintains its sustainability by developing specific ways of life (internal factors) and building an 
extensive social network (external factors). It demonstrates that community-based exploration and experiments with alternative lifestyles can address the challenges of sustainability. It further suggests that as a conceptual framework, sustainability has played an essential role in embodying the successes or failures of self-organizing communities.

\section{Literature Review}

\subsection{Sustainability and Self-Organizing Communities}

Sustainability is generally considered to be a narrative of top-down governance produced by government and academia. A number of social institutions around the world have proposed specific definitions of sustainability since 1970s. Although the focus of their definitions is different, it can be attributed to four main areas of concern — quality of life, present and future generations, justice and equity and living within ecosystem limits [11]. The Earth Charter, which has evolved into an international consensus document, emphasizes the importance of major socio-cultural changes for achieving sustainability in its discourse. To be specific, it points out that sustainability is incompatible with the hegemonic ideology and institutional parameters of industrial capitalism, which requires the practice and articulation of an alternative vision of political economy, as well as a strong commitment to realizing it [12]. Other international institutions also raise the need for value-sharing communities to alleviate a fundamental tension between ideas and practices in the narrative of sustainability.

Since then, a growing number of scholars have suggested that community-based social experiments will be essential to striving for sustainability. According to Agyeman, a more grassroots and bottom-up process is needed to supplement top-down institutional action and to provide the necessary conditions for sustainable development of communities. Fernando further used the term islands of sustainability to describe its implementation at the community level. This vision shows greater recognition of the significant role played by communities in advocating counter-hegemonic intellectual and material practices [13] and changing attitudes and behaviors towards social and environmental responsibility [7].

In the contemporary commune, movements characterized by diversity, self-organizing communities best embody the sustainability orientation. The history of self-organizing communities can be traced back to more than 2000 years ago, with the most typical groups pursuing freedom of spiritual practice [14]. Homakoeion is considered to be a typical self-organizing community established in southern Italy around $525 \mathrm{BC}$ - several hundred individuals sought to create the ideal society through communal ownership and mystical, intellectual practices [15]. The self-organizing communities spread throughout Europe in the 12th and 13th centuries, as well as the 16th and 17th centuries. From the 17th to the 19th century, the Americas provided a particularly fertile ground for Europeans seeking to be free from religious persecution and oppression [16]. Communal studies scholars recognize that the construction of self-organizing communities in the United States has mitigated the social impact of early industrial capitalism and provided a variety of utopian designs to improve social life following the Enlightenment.

Apart from Europe and America, the construction of self-organizing communities in Australia and New Zealand has continued since the 19th century [17]. Kibbutzim became an essential part of Israel's national construction project in the early 20th century. Moshav is another popular form of self-organizing communities in Israel, which refers to more individualized cooperative agricultural settlements. Kibbutzim and Moshav nowadays are two primary, less strictly communal forms in Israel. The unique history of self-organizing community building has also been recognized by Canada, India and many Latin American countries [15]. Across various social contexts, the cooperative, participatory and more sustainable living remains an overall approach [7].

In the early 20th century, self-organizing communities spread to East Asia, represented by Japan and Korea. In Japan, there are a number of independently formed self-organizing communities, both religious and secular [14]. One of the famous communities is Atarashiki Mura (New Village) founded by Mushakoji in 1918. It encouraged members to pursue self-actualization to the fullest 
extent, which had a great influence on the Communist social experiment of that era in China [18]. The flourishing of the student movements since 1919 led to the establishment of new self-organizing communities. Although they were less visible than those in Western countries, dozens of loosely structured communities had been set up in rural China. Some experiments with political ideas have attracted great attention from reformers, but most of them vanished quickly [19].

Since the mid-20th century, a large number of self-organizing communities have been established in urban suburbs of developed countries in Europe and North America with an emphasis on human rights and environmental sustainability. Such communities are made up of people who share the same ideals and values. The lifestyles they pursue and the ideology they advocate are regarded as experimental social fields because they are opposed to unsustainable ideological and political-economic forces [16]. Self-organizing communities are therefore defined as economically cooperative social entities and are usually characterized by small scale, consensus, co-construction, co-creation, and utopian preferences. This shows an attempt to build alternative lifestyles by setting up specific economic, political, and social rules.

\subsection{Eco-Villages and Co-Housing}

Some scholars divided self-organizing communities into different types based on a number of dichotomies—secular and religious, urban and rural, communal and cooperative, charismatic leadership and democratic governance [20]. In order to transform the above concepts or goals into effective practices, self-organizing communities are connected to sustainability in four ways-community design, social interaction within the community, social support within the community and a shared sense of identity with the community [7]. Sustainability-oriented self-organizing communities embody these connections through multi-faceted forms, including ecological villages, co-housing, land trust residences, communes, student cooperatives, and residential cooperatives. According to statistics in North America, the number of alternative communities-especially the two most prevalent forms of cohousing and eco-villages - has increased more than eightfold in the past twenty-seven years, from 304 communities in 1987 to 2456 communities in 2014 (the Fellowship of Intentional Communities Directory).

Based on numerous empirical studies in multiple countries, cohousing is considered the fastest growing and most accessible sector of the community movement [21]. Since the final decades of the 20th century, a large number of co-housing communities have been built to search alternative ways to strike a balance between individualism and communalism, privacy and community involvement and social diversity and unity of purpose that has made them a fairly attractive option to the mainstream [7]. Most of them are interconnected through diverse sustainable innovations, such as voluntary simplicity, green economic cooperation, organic farming, peace and social justice activism, alternative energy and technology. Within communities, people are allowed to be directly involved in its design and planning, and actively address the challenges of sustainability in their everyday lives. They have a certain share of the production, consumption and maintenance of food, energy, land and other resources while having independent income and living space.

The ecovillage is another increasingly popular type of self-organizing community that aspires to create a more humane and sustainable way of life-consuming less, recycling more wastes, and generally living with much less impact on the environment [7]. Influenced by cohousing movements, the Global Ecovillage Network (GEN) was established in 1995. It defines eco-villages broadly as human scale, full-featured settlements in which human activities are harmlessly integrated into the natural world in a way that is supportive of healthy human development and can successfully continue into the indefinite future. This definition depicts a larger vision of a village that can accommodate hundreds of people and provide employment opportunities, as well as education and medical services for them. It even aims to become a practical and replicable sustainability system that can be promoted at the national level. However, such an aspiration does not seem to be a priority for eco-villagers [22-24]. 
Instead, the residents mainly focus on individual achievement of a sustainable lifestyle or, at most, the pursuit of sustainability at the community level [25].

Cohousing and eco-villages offer an important reference for the development of new alternative communities in China. Over the past two decades, a large proportion of self-organizing communities have undergone planning reforms. To be specific, earlier generations were often profoundly anti-materialists, which sometimes led to a refusal or neglect to consider material issues. It caused many groups to fail to survive. The newer eco-village and co-housing groups have learned from the experiences of those pioneers and have attempted to build economic and social sustainability into their community design [3]. In many cases, the community founders still retain an anti-materialist ethos, but they do seriously consider how to maintain themselves in material terms. Therefore, self-organizing communities have become somewhat decentralized, giving members a good sustainable mix of freedom and togetherness [8]. In this study, a specific self-organizing community in South China, AnotherLand, embodies the main characteristics of cohousing and eco-villages mentioned above, including the balance of individualism and communalism, the maintenance of ecological, cultural and economic sustainability, and the pursuit of equality and social justice. A detailed description of this community will be provided in the next section.

\section{Methodology}

\subsection{Data Collection}

As an ethnographic study, in-depth interviews and participant observation were chosen as the primary data collection techniques in this research - the relationship between these two methods is mutually supportive and mutually reinforcing. Creswell and Punch pointed out that the purpose of ethnography is to portray the everyday experiences of individuals by actively participating in their activities, to immerse oneself in the context where the research takes place, and to understand how others live from their point of view [26]. In this case, I spent significant periods of time interacting and communicating with the community members. I participated in their farming, planting, building, and other daily activities, which not only made me experience their specific alternative way of life but also allowed me to gain their trust and generate deeper insights.

Formal interviews were conducted with eighteen selected participants from the community members in AnotherLand. There were eight females and ten males, including two couples. Singles accounted for half of the participants in this case because they usually enjoyed higher degrees of freedom and were less bound by intimate relationships. Participants joined AnotherLand at different times, staying for months to years. Four of them have withdrawn from the community during the study. All interviews were conducted in Mandarin and translated into English before data analysis. The average duration of interviews was two to three hours. Table 1 shows the characteristics of the participants in this research.

The personal background of the eighteen participants showed great complexity and diversity that was difficult to generalize. In view of the rich details of this self-organizing community, thematic analysis and narrative analysis played an essential role in interpreting the participants' personal experiences of everyday life, as well as their specific lifestyle experiments for maintaining the sustainability of this self-organizing community. It was also through ethnographic approaches that community-based attempts to address sustainability challenges were examined [27]. 
Table 1. Characteristics of the participants.

\begin{tabular}{ccccc}
\hline Pseudonym & Gender & Age & Marital Status & Length of Stay \\
\hline Tang & Male & 29 & Married & 6 years \\
\hline Jane & Female & 34 & Married & 5 years \\
\hline King & Male & 32 & Single & 3 years \\
\hline Tong & Female & 39 & Married & 3 years \\
\hline Ceng & Male & 42 & Divorced & 8 months \\
\hline Sherry * & Female & 29 & Single & 11 months \\
\hline Rong * & Male & 28 & Single & 2 years \\
\hline Park & Male & 34 & Single & 2.5 years \\
\hline Gold & Male & 27 & Single & 4 years \\
\hline Kuan & Male & 38 & Married & 2 years \\
\hline Spring & Female & 37 & Married & 2 years \\
\hline Ice & Female & 26 & Single & 4 months \\
\hline Dou & Female & 40 & Divorced & 1.5 months \\
\hline Tiger & Male & 30 & Single & 6 months \\
\hline Zen & Female & 43 & Married & 5 years \\
\hline Fan* & Female & 27 & Single & 4 years \\
\hline Yu & Male & 57 & Divorced & 3 years \\
\hline Kobe * & Male & 25 & Single & 3 months \\
\hline Note: ${ }^{*}$ Participants who have left the community during the fieldwork.
\end{tabular}

\subsection{Description of A Self-Organizing Community}

AnotherLand was established by several young artists in 2010. It is one of the first self-organizing communities in mainland China. They initially set up the community on a mountain to explore a self-sufficient way of life. Their social experiments successfully attracted the attention of various individuals, groups and organizations. In 2015, the members of AnotherLand reached a partnership with the Foundation and moved their community to Minhou County, Fuzhou. The Foundation was a 5A level social organization in China, that was dedicated to building a professional and transparent cross-border public welfare platform. The Foundation rented 500 acres of cultivated land in Wong Village from the local government for a use period of 20 years. It provided the farmland to five ecologically themed organizations, including AnotherLand. The cooperation with the Foundation has brought many benefits and conveniences to them, such as reducing the cost and risk of signing long-term land lease contracts with the third part. It also provided an extensive network for relevant organizations to carry out various economic and cultural activities. Correspondingly, AnotherLand and other member organizations needed to comply with the three principles formulated by the Foundation-being good for the land, good for the village, and good for the partners, and to take eco-environment protection and sustainability as shared themes.

In the next few years, Anotherland refurbished a five-story building in the residential area of the Wong Village. The map can be seen in Figure 2. The building offered a collective accommodation area, a shared kitchen and meeting rooms, which was regarded as a public space for members to live together. Additionally, the community members have successively renovated old houses abandoned by the former villagers and built several ecological buildings in the non-planting areas of the village. In order to improve architectural function, they dug a reservoir hundreds of meters from the building and installed a water purification device. They also placed solar panels nearby to meet residents' daily lighting needs. In early 2018 , they pulled wires to the ecological buildings, which provided 
household's electricity for themselves. Although most of the expenses of private eco-houses needed to be borne by individuals, the required labor was usually shared by community members.

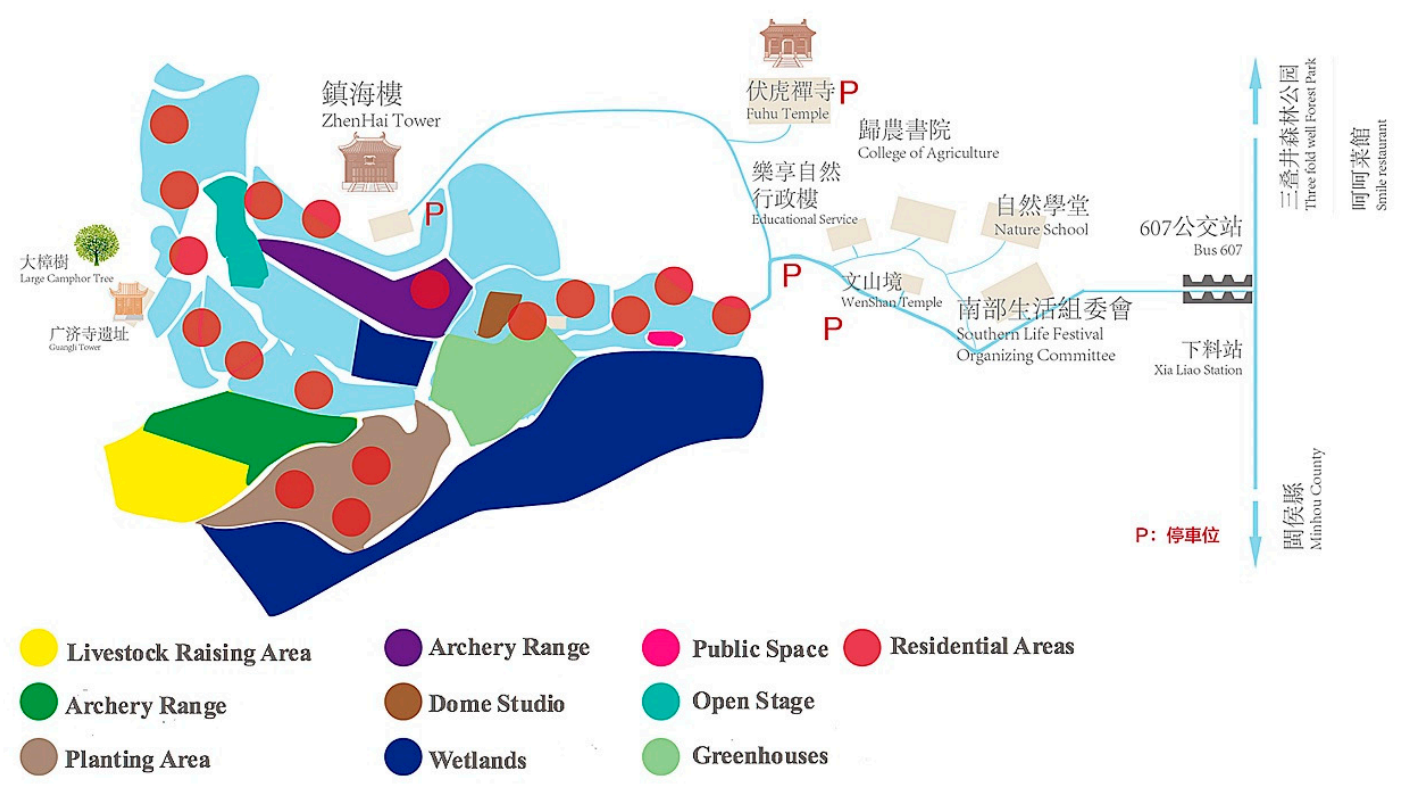

Figure 2. The Map of Wong Village.

In AnotherLand, the number of formal members was maintained at ten to fifteen. Visitors were welcome to live with community members to experience their specific lifestyles, with a charge of fifty Chinese yuan per day (about eight U.S. dollars). There were more visitors in summer and autumn (about 15-20 people per month) than in winter and spring (less than 10 people per month). Most visitors stayed in the community for only a few days. There were no specific requirements to apply to be community members. The evaluation period of prospective members was three months. During this period, the applicants were required to participate in the daily work and activities of the community, such as farming, cooking and renovating houses. At the same time, the current community members needed to assess whether the applicants recognized the community values, whether they were excellent communicators, whether their personalities were suitable for the collective life, and whether they had the strengths and skills to support their choice. If the applicants had the willingness to pursue membership after the evaluation period, a democratic voting process which included a meeting of community residents would decide whether they have the right to join public affairs and to share community resources.

A ten-year plan has been proposed by AnotherLand to build a sustainable self-organizing community in the countryside. In terms of farming, more than ten acres of land were used to grow grain and vegetables, and several acres of land were planned for planting fruit trees. As for ecological architecture, the community planned to build energy-saving houses for each family unit. All required labor would be shared by members, volunteers, and visitors. To maintain economic sustainability, the community organized various activities such as the Winter Life Festival, Natural Education Camp, Country Art Carnival, and provided special courses for visitors to learn and practice organic farming. In terms of public affairs, AnotherLand intended to build a credit system so that members could exchange their labor and services for credits. Their accumulated credits could be further used to redeem food and daily necessities at a specific rate. More importantly, this ten-year plan connected individual-level everyday practices with organizational-level community building. The next section will show the findings on the sustainable development of AnotherLand in China's countryside. 


\section{Results}

\subsection{Experiments of Specific Lifestyles}

In this case, members of AnotherLand developed an alternative mode of the Half-Farmer and Half- $X$ lifestyles. This special life-work pattern was established and advocated by a Japanese activist-it aims to solve contemporary social problems by utilizing sustainable agriculture and individuals' abilities. Naoki Shiomi established the Half-Farmer and Half-X Institute in April 2000 and promoted this idea as the most valuable lifestyle of the 21st Century. It fully embodies the idyllic characteristics that are popular in contemporary commune movements, which is a less hurried lifestyle, a more close-knit community, as well as a stress-free environment away from the excesses and constraints of the city [28]. In AnotherLand, participants' experiments in the Half-Farmer and Half-X lifestyles gave a concrete image of the sustainable development promoted by the self-organizing communities.

To be specific, the first part of Half-Farmer represents an eco-friendly way of production that can be implemented on different scales, from small to large, including backyard gardens, small fields, and ecological villages. To guarantee the quality of land, community members must abide by the farming guidelines for organic food. They were asked to avoid using chemical fertilizers and pesticides, as well as to make compost with food waste and other organic matter. As for the second part, Half- $X$ is the variable in this lifestyle model, which is usually derived from an individual's strengths and interests, such as art, education, medicine, or technology, as can be seen in Figure 3. It is not only the main source of income for their everyday life but also an important way to maintain positive connections with the outside world. In various forms of Half- $X$, areas related to environmental protection and cultural innovation were particularly encouraged. In addition, the pursuit of specific Half- $X$ activities enabled community members to obtain a sense of fulfillment. A rich narrative of the Half-Farmer and Half- $X$ has been produced by the eighteen participants to show their individualized lifestyle experiments in this self-organizing community. According to the coding of interview materials, their lifestyle experiments mainly focused on three themes; namely, organic farming, natural education, and lifestyle transformation.

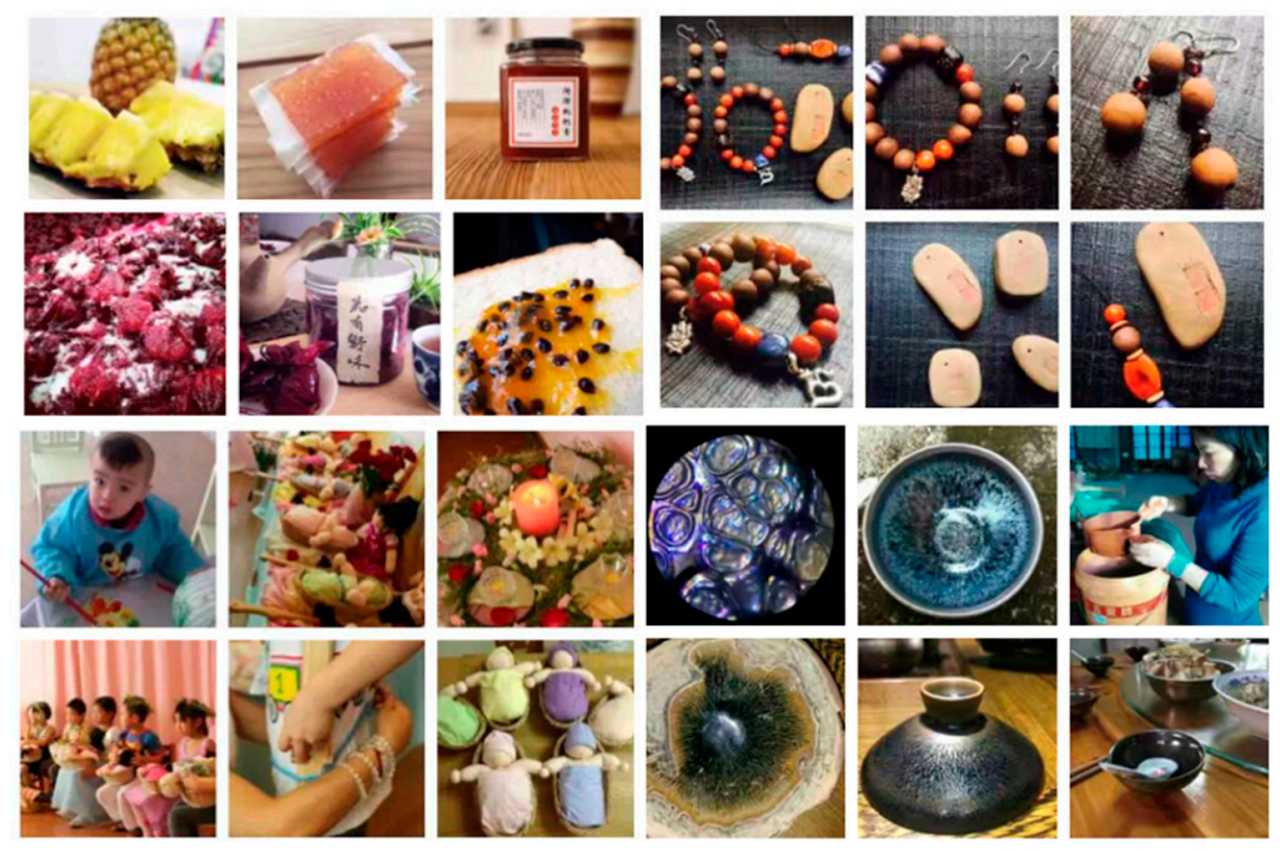

Figure 3. The Half-X of Self-organizing Communities. 


\subsubsection{Organic Farming}

A considerable proportion of community members regard food safety and environmental health as their primary appeal in terms of quality of life. Especially for middle-class nuclear families, reducing the intake of pesticides, hormones, haze, and exhaust gas by the next generation has become their main motivation to leave the city. There were four young parents among my interviewees, and they all agreed that they joined this self-organizing community for the healthy growth of their children. Tong (38) was one of them, who raised a 9-year-old son. After she became pregnant, Tong decided to quit her job and join an ecological community where she was allowed to grow fruits and vegetables independently.

Our (urban people) choice of food depends on suppliers like supermarkets and restaurants. I often feel anxious because I don't know how the food is produced, even though they usually look clean. So, it is necessary to shorten the food miles (the distance from the field to the table). My solution is to grow vegetables for my family. Now I have a fixed timetable to take care of the garden. I can follow their growth process and make sure that the food served on my table is reliable. (Tong, 38)

In order to ensure a balanced diet in daily life, Tong and some members have developed a cooperative production strategy. They distributed two to four kinds of vegetable seeds to each family for planting. When it came to harvest, they exchanged different ingredients with each other. As for those foods that were difficult to grow, such as cereals and nuts, Tong would buy them from trusted friends in other ecological organizations. In this way, they formed a sustainable production and distribution network to guarantee a variety of diets in this self-organizing community.

\subsubsection{Natural Education}

Although these young parents attempted to protect their children by offering them an eco-friendlier lifestyle, they had to face many disadvantages caused by leaving the city. One of the disadvantages that cannot be ignored was that their choice of educational resources was significantly limited. In rural areas, primary and secondary schools were unable to provide a high-quality education like those in big cities, especially in bilingual classes and hardware facilities. It seemed that families in this self-organizing community were caught in a dilemma in raising children. However, my interviewees have formed their unique views on this issue during their experiments with Half-Farmer and Half-X lifestyles.

Nature-deficit disorder is a common problem for children in the city nowadays. It refers to the lack of natural exploration and experience in their growth. It will affect children's perceptivity, aesthetic and intellectual development. Children in the countryside can have more opportunities to get close to animals and plants, and even learn some agricultural knowledge from rural people. This part of knowledge is acquired through the mainstream education system. I think children who grow up in a natural environment tend to have a happier childhood and a more positive personality. Their physical and mental health is more important than anything else. (Spring, 37)

Most of the children who lived with their parents in AnotherLand have not reached the age to attend school. Family-based teaching was widely regarded by community members as an alternative to primary or even middle school education. However, when it came to the university level, parents were asked to think carefully about whether to continue their children's natural education that was significantly different from mainstream pedagogy. Especially in the face of fierce competition in the labor market, alternative education needed to equip the younger generation in such communities with high-quality knowledge and training to choose their way of life [29]. Therefore, the improvement and perfection of alternative education, such as natural education in this case, has become one of the essential conditions for the sustainable development of self-organizing communities.

\subsubsection{Lifestyle Transformation}

Given that most of the community members had an urban background, they usually lacked experience in rural life, such as knowledge and skills in farming. This meant that they had to spend a 
certain amount of time and effort to adapt to a different living environment. Jane (34) used to be a senior manager before joining this self-organizing community. She admitted that she has undergone a difficult period of lifestyle transformation. Among many changes, what impressed her most was the interaction with land and nature.

I do believe nature is an extension of our body and mind. When I was farming, I feel so touched to see things grow out of the ground. I think it is a spiritual comfort that can bring vitality and hope to the cultivator. I would like to admit that my attitude towards material [things] has also changed. I used to have an excessive pursuit of material life that can be quite extravagant and wasteful. Rural life contains many philosophies that teach me to respect the land, cherish the labor, and treasure the food. So, the degree of life satisfaction in this type of self-organizing communities is very high. (Jane, 34)

Jane pointed out that she got rid of the habit of over-consumption and extravagance influenced by the consumerism prevailing in the city. By experimenting with a specific lifestyle, she described the positive impact that this self-organizing community brought to her and answered questions about who she was and what she wanted-the most important thing is that I can understand myself better and respect my own feelings. As a result, the mode of Half-Farmer and Half-X lifestyles improved the individual's agency and gave them spiritual satisfaction. Although the participants in such a self-organizing community were highly mobile, the changes and growth it brought to members and visitors made it consistently attractive. It enabled AnotherLand to maintain its sustainability in terms of member size.

\subsection{Social Networks}

In addition to experiments with the Half-Farmer and Half-X lifestyles, AnotherLand also maintained an active social network with the outside world. By taking eco-environment protection and sustainability as shared values, it cooperated with other self-organizing communities and ecological activists, as well as the broader cultural organizations in a number of areas. The extensive networks gave the community members access to various roles, resources, and forces in the rural areas of South China. They also gained more opportunities to expose and promote the concept of self-organizing communities to the public. Since 2017, concerns from different sectors of society have led to this alternative lifestyle being associated with more diverse and sustainability-oriented narratives.

\subsubsection{Economic Activities and Scale Effect}

Given that the themes and interests of AnotherLand and other organizations are interrelated, they sought development through drawing resources and capital from each other, which blurred the boundaries of fields and formed a win-win situation [30]. This was particularly evident in a commercial context. Taking the Farmers Market as an example, it is a cultural innovation project initiated by AnotherLand and several related organizations. An example of this commercial activity is illustrated in Figure 4. The Farmers Market provides a platform for small business owners, small farmers, craftspeople, and ecological communities to gather together to do more business.

They offered a wide range of products and services in the economic network of the new rurality. Since these organizations were concentrated in Fuzhou, the products and services offered by them were also of mutual benefit. For example, guests who signed up for parent-child courses at the Waldorf Nature School would be eligible to participate in AnotherLand's Winter Festival free of charge. By organizing commercial activities similar to the Farmers Market, AnotherLand has benefited a lot from its scale effect and accumulated the necessary capital for basic living needs. It also drove the community members to make some cross-domain attempts, such as part-time or volunteer work in other organizations. 


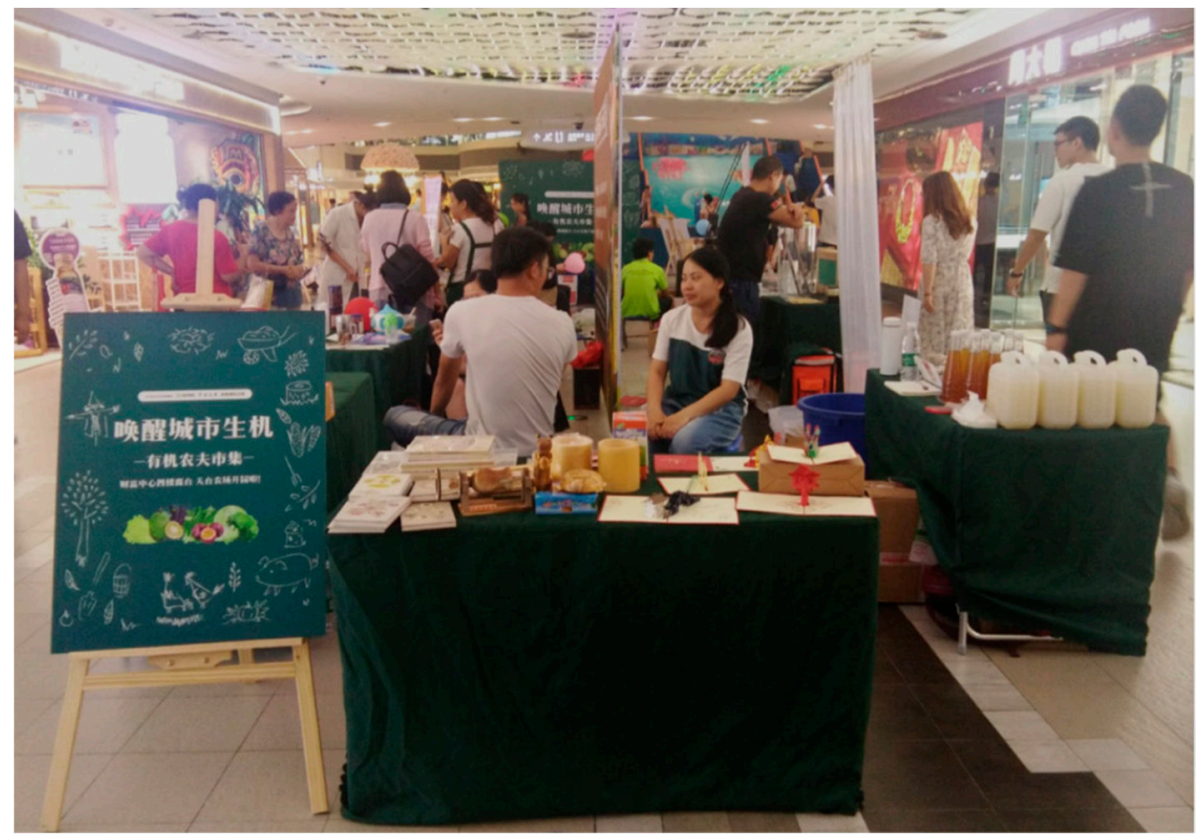

Figure 4. The Farmers Market in Fuzhou.

Ultimately, these independent and interrelated organizations merged into a larger whole, from which the values and rules unique to this integrated field were generated [31]. Since AnotherLand held a strong appeal for the public, it had a great influence on shaping the values in the field. Specifically, AnotherLand's concept of exploring alternative lifestyles and building self-organizing communities has been strongly conveyed to other ecologically themed organizations and the wider public. It played an essential role in connecting resources and attracting investment from the outside world, which contributed to constituting the field as a meaningful world, a world endowed with sense and value, in which it is worth investing one's energy. [32].

\subsubsection{Interaction with the Locals}

As mentioned above, a large percentage of the local residents in Minhou County had moved to the city. The population in the village now consisted of three main components: migrant farmers, participants of the social organizations, and a small number of local villagers-they were no longer relying on agriculture for a living, but instead were doing small business in a nearby town. Given the large economic and cultural differences between these social groups, they showed different attitudes and opinions on certain issues, such as human-earth relationships, planting patterns, and development strategies in rural areas. This inevitably led to misunderstandings and conflicts in this shared space. Given that the community members had obvious advantages in cultural and social capital, their social status was relatively higher than other groups. They did, therefore, find it difficult to integrate into the local lifestyle or develop a sense of identity with others.

Specifically, my participants believed that the local agricultural activities had a negative impact on the organic farming advocated by this self-organizing community. According to their eco-friendly principles, the use of pesticides and chemicals by traditional farmers was not conducive to soil conservation and ecosystem regulation. To alleviate the contradiction in the idea of farming, the community often invited migrant farmers and local residents to attend courses about organic farming and encouraged them to reduce their use of chemical fertilizers. However, due to the high time and labor cost of maintaining the cultivated land, it was unrealistic for farmers to make a living through organic farming in the short term. Even though groups staying in the village had different drivers and purposes, community members still believed that it was necessary to increase mutual understanding 
among different parties in the village. They pointed out that they would like to build a sustainable living environment with the local community rather than a parallel society against them [33].

\subsubsection{Responses to the Policy of New Rurality}

Since the land of Wong village belonged to the local government, the construction of this self-organizing community needed to comply with its rules and regulations. For example, the Minhou County government has banned new permanent buildings in its subordinate villages since 2017 . This policy led to the dismantling of two ecological buildings of AnotherLand. This can be seen in Figure 5. The local governments asked them to remodel these houses in terms of materials and structures to meet the standards of non-permanent buildings. At the same time, the community also needed to submit the requested documents (e.g., CAD drawings and qualifications) for the new ecological buildings to the Urban and Rural Planning Bureau for administrative review. In the interview, the person in charge of AnotherLand's architecture pointed out that with the increasing popularity of self-organizing communities in recent years, it has become a pioneer of rural transformation in South China.

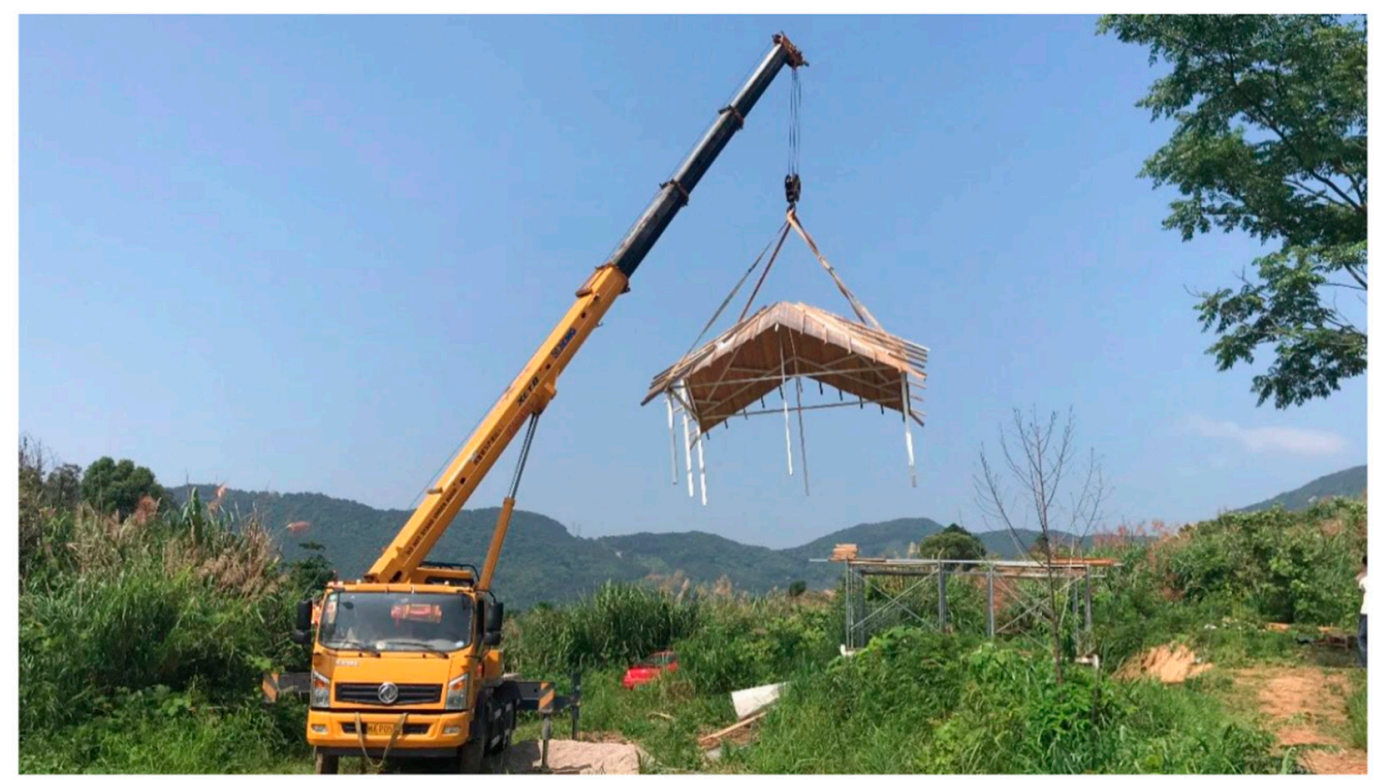

Figure 5. Demolition site of AnotherLand.

The concept of new rurality emphasizes the diversification of activities and livelihoods beyond the agricultural [34]. In the Chinese context, this term first appeared in 2005, which describes the new conditions in rural areas and proposes a new urban-rural relationship. In 2017, the Chinese government has once again strengthened several implementation plans for revitalizing rural areas. Fujian Province takes community building and cultural conservation as its development strategy of new rurality construction, acknowledging that rural areas are no longer synonymous with agriculture [35]. In view of this, the development of AnotherLand was getting more and more attention from the local government. Their lifestyle experiments have also been affected by the rural revitalization strategy in Minhou County-it encourages the rise of retail, rural tourism, lifestyle migration and other social organizations based on new urban-rural interactions [36-38]. To ensure the sustainability of their self-organizing community, AnotherLand invoked the local government's idea of new rurality in its ten-year plan. In 2018, AnotherLand took over a rural culture conservation project in Minhou County. By undertaking projects from local governments, AnotherLand has extensively interacted with various entities (e.g., social enterprises and government agencies) that play important roles in the policy of new rurality. 


\section{Discussion}

According to Metcalf, perhaps the most compelling measure of success for self-organizing communities is the sheer ability to survive [39]. At the 1993 meeting, the International Communal Studies Association (ICSA) also suggested that:

In the process of considering what constitutes success, it was essential to consider the extent to which communities are capable of changing over time to adjust to the changed needs of the community, its members, and the wider society [17].

This article uses sustainability to summarize the above description of the successes or failures of self-organizing communities. Taking AnotherLand, a self-organizing community in South China, as a specific case, its sustainable development is presented in two main aspects: (1) the experiments of specific lifestyles (internal factors) and (2) the construction of social networks (external factors).

In terms of experiments in specific lifestyles, community members developed the mode of Half-Farmer and Half-X. On the one hand, Half-Farmer, or small-scale ecological farming, shortened the distance from the source of food to the table and enabled the deep involvement of participants in all stages of food production, including the restoration of cultivated land and the production of compost. On the other hand, the interaction between participants and farmland brought them spiritual comfort, which played an important role in promoting their well-being in this self-organizing community. For the other part of Half- $X$, community members expanded a variety of economic activities according to their own strengths and skills. On this basis, they improved the cultural creativity and aesthetic sensitivity to their alternative lifestyles. The exploration of Half- $X$ not only provided basic economic security for community development but also made this self-organizing community connected with more diverse fields. More importantly, the highly individualized lifestyle experiments helped community members better understand themselves, which brought them personal change and growth. It enabled this self-organizing community to maintain its sustainability in terms of member size.

In terms of the construction of social networks, AnotherLand has built a complex network with social organizations, local communities, and government agencies. First of all, this self-organizing community and relevant social organizations provided complementary goods and services in specific areas. It not only enabled a scale effect for economic activities with the theme of ecology, but also effectively outputted the concept of alternative lifestyles that they advocated. Secondly, this self-organizing community attached importance to a mutual understanding with local groups. Members of the community tried to share the methods of organic agriculture (such as the Permaculture system) with traditional farmers. They also provided local people with training in relevant courses. In addition, unlike the self-marginalized commune movement or green movement in the 1970s and 1980s, the contemporary self-organizing communities intend to generate more exchanges and interactions with the mainstream society. This was well reflected in AnotherLand's active cooperation with the local government. It has consciously participated in the discourse of the construction of new rurality, such as numerous activities of old house renovation, rural cultural conservation, and local community building. Establishing social networks helped this self-organizing community to ensure its sustainable development at the institutional level.

The above findings demonstrate that the self-organizing community in this study can maintain its sustainability at both the agency level and the structure level. By experimenting with alternative lifestyles of the Half-Farmer and Half- $X$, the community ensures its sustainability in terms of its daily diet, basic expenses, membership size, and spiritual well-being. At the same time, the community has also improved its cultural (interaction with local people), economic (business with other ecological organizations) and political (cooperation with local governments) sustainability by building social networks. This shows that this self-organizing community is capable of changing over time to adjust to the changed needs of the community, its members, and the wide society [17]. It also means that the extent to which self-organizing communities can implement sustainability is closely related to their ability to survive. Therefore, this research argues that sustainability as a conceptual framework can 
effectively embody the success or failure of self-organizing communities, and should be emphasized both empirically and theoretically in community studies.

Author Contributions: The author was responsible for the writing, review and editing. The author has read and agreed to the published version of the manuscript.

Funding: This research received some funding from The Hong Kong Polytechnic University to cover the fieldtrip in South China.

Conflicts of Interest: No potential conflict of interest was reported by the author.

\section{References}

1. Moran, E.F. People and Nature: An Introduction to Human Ecological Relations; John Wiley \& Sons: Hoboken, NJ, USA, 2016.

2. Moylan, T. Demand the Impossible: Science Fiction and the Utopian Imagination; Methuen: New York, NY, USA, 1986.

3. Sargisson, L. Sustainability and the Intentional Community: Green Intentional Communities. In The Transition to Sustainable Living and Practice; Emerald Group Publishing Limited: Bingley, UK, 2009; Volume 4.

4. Davis, J.C. Utopia and the Ideal Society; Cambridge University Press: Cambridge, UK, 1981.

5. Levitas, R. The Concept of Utopia. Cap. Class 1990, 14, 158-161.

6. Sargent, L.T. Three faces of utopianism revisited. Utop. Stud. 1994, 5, 1-37.

7. Meltzer, G. Sustainable Community, Learning from the Cohousing Model; Trafford publishing: Bloomington, IN, USA, 2005.

8. Gardner, H. The Children of Prosperity: Thirteen Modern American Communes; St Martin's Press: New York, NY, USA, 1978.

9. O'Reilly, K. Intra-European Migration and the Mobility-Enclosure Dialectic. Sociology 2007, 41, 277-293. [CrossRef]

10. Qiu, S.; Liang, K. Study on Ecological Security Evaluation of Idle Farmland in Minhou County. Chin. J. Agric. Resour. Reg. Plan. 2018, 39, 93-98.

11. Agyeman, J. Sustainable Communities and the Challenge of Environmental Justice; NYU Press: New York, NY, USA, 2005.

12. Fernando, J.L. The Power of Unsustainable Development: What Is to Be Done? (Preface) (Author Abstract). Ann. Am. Acad. Political Soc. Sci. 2003, 590, 6-34. [CrossRef]

13. Bebbington, A. Social Capital and Rural Intensification: Local Organizations and Islands of Sustainability in the Rural Andes. Geogr. J. 1997, 163, 189-197. [CrossRef]

14. Christensen, K.; Levinson, D. Encyclopedia of Community: From the Village to the Virtual World; Sage Publications: California, CA, USA, 2003.

15. Metcalf, B. The Findhorn Book of Community Living; Findhorn Press: Moray, Scotland, 2004.

16. Lockyer, J.P. The Sustainability and Utopianism. Ph.D. Thesis, UGA, Athens, GA, USA, 2007.

17. Sargisson, L.; Sargent, L.T. Living in Utopia: New Zealand's Intentional Communities; Ashgate: Aldershot, UK, 2004.

18. Karen, C.; David, L. Encyclopedia of Community: From the Village to the Virtual World. Ref. Rev. 2005, 19, $24-25$.

19. Xin, L. “Ling Pi Xi Jing” De She Hui Gai Zao: Xin Cun Yun Dong Yu Min Guo Zao Qi Du Shu Ren De Xiang Cun Xiang Xiang. Soc. Sci. Res. 2016, 2, 159-173.

20. Kozeny, Geoff. In Community, Intentionally. In Communities Directory; Fellowship for Intentional Community, Ed.; Fellowship for Intentional Community: Rutlege, MO, USA, 2005; pp. 12-17.

21. McCamant, K.; Durrett, C. Creating Cohousing: Building Sustainable Communities; New Society Publishers: Gabriola Island, BC, Canada, 2011.

22. Holleman, M. Individuality in Community at the EVI. Master's Thesis, VU University, Amsterdam, The Netherlands, 2011.

23. Liftin, K. Reinventing the future: The global ecovillage movement as a holistic knowledge community. In Environmental Governance: Power and Knowledge in a Local-Global World; Kutting, G., Lipschutz, R., Eds.; Routledge: London, UK, 2009; pp. 124-142. 
24. Gesota, B. Ecovillages as Models for Sustainable Development: A Case Study Approach. Master's Thesis, Albert-Ludwigs-Universitat, Freiburg, Germany, 2008.

25. Kusakabe, E. Advancing Sustainable Development at the Local Level: The Case of Machizukuri in Japanese Cities. Prog. Plan. 2013, 80,1-65. [CrossRef]

26. Creswell, J.W. Research Design: Qualitative \& Quantitative Approaches; SAGE: Thousand Oaks, CA, USA; London, UK; New Delhi, India, 1994.

27. Marcus, G.; Fischer, M. Anthropology as Cultural Critique: An Experimental Moment in the Human Sciences, 2nd ed.; University of Chicago Press: Chicago, IL, USA; London, UK, 1999.

28. Matthews, H.; Taylor, M.; Sherwood, K.; Tucker, F.; Limb, M. Growing-up in the Countryside: Children and the Rural Idyll. J. Rural Stud. 2000, 16, 141-153. [CrossRef]

29. Aron, L.Y. An Overview of Alternative Education; First in a Series of Papers on Alternative Education for the U.S. Department of Labor; The Urban Institute: Washington, DC, USA, 2006.

30. Leander, K.; Phillips, N.; Taylor, K. The Changing Social Spaces of Learning: Mapping New Mobilities. Rev. Res. Educ. 2010, 34, 329-394. [CrossRef]

31. Bi, T.-Y. On the Bourdieu's Theory of Field-Habitus. Acad. Explor. 2004, 1, 32-35.

32. Bourdieu, P.; Wacquant, L. An Invitation to Reflexive Sociology; Polity: Cambridge, UK, 1992.

33. Leonard, P. Landscaping Privilege. Being British in South Africa; Twine Andardener, F.W., Geographies of Privilege, Eds.; Routledge: London, UK, 2013; pp. 97-121.

34. Urquijo, P.; Bocco, S.; Boni-Noguez, G. New rurality and the experience of place: The small rural locality of La Niña, Buenos Aires, Argentina. GeoJournal 2018, 83, 1301-1315. [CrossRef]

35. Peng, H.; He, R.; Weng, X. Collaborative governance model of tourism urbanization in rural areas: A case study of Shuiji village in Taining County, Fujian. Geogr. Res. 2018, 37, 25-40.

36. López, V.T. Agroindustrialización y Nueva Ruralidad en América Latina. Una reflexión para la comprensión de la realidad rural contemporánea. Estud. Rural. 2013, 1, 11.

37. Burkham, J. The City Will Come to Us: Development Discourse and the New Rurality in Atotonilco El Bajo, Mexico. J. Lat. Am. Geogr. 2012, 11, 25-43. [CrossRef]

38. Kay, C. Reflections on Latin American Rural Studies in the Neoliberal Globalization Period: A New Rurality? Dev. Chang. 2008, 39, 915-943. [CrossRef]

39. Metcalf, W.J. Intentional Communities in Australia and New Zealand. In Encyclopedia of Community: From the Village to the Virtual World; Christensen, K., Levinson, D., Eds.; Sage Publications: Thousand Oaks, CA, USA, 2003; Volume 2, pp. 705-711. 